\title{
Influencing Factors and Countermeasure Analysis of Autonomous Learning of College Students' English Curriculums
}

\author{
Jinzhu Zhao \\ Shaanxi Polytechnic Institute, Xianyang Shaanxi, 712000, China
}

Keywords: University student, English course, Autonomous learning, Influence factor

\begin{abstract}
English autonomous learning has an extremely important influence on strengthening and improving the overall English level of college students, which can steadily enhance learning enthusiasm and initiative of students in later stage of their English learning, and then get the best learning effect. But at present, the college students in our country are influenced by the traditional education mode and have a relatively poor learning ability, which is not conducive to the full development in the later stage. So this thesis starts with the influence factors of self-learning ability of college students' English course , and explores the countermeasures of improving students' self-study ability, hopes to provide some supports and references for the reform of English teaching in colleges and universities.
\end{abstract}

\section{The connotation of Autonomous Learning}

In the early 80's, Hocker published the book Autonomy and Foreign Language Learning combined with his many years of research experience, introduced the concept of autonomous learning in language teaching field for the first time, which has a very important impact on the development of language teaching field. Hocker proposes in the study that self study ability means the consciousness and ability of self learning activities, and divides it into five aspects painstakingly: Learners should have a good learning attitude ; master learning skills of different knowledge during learning process; exploit self potential and capacity of receiving knowledge to the upmost; responsibility for self learning and the right for choosing suitable learning materials combined with their actual needs .Huttenen also points out in his study that self study can be defined as the cognitive and ability that learners will be voluntary for study during learning process, that is to say, self learning can be recognized as a correct and positive learning attitude., it can also be considered as a kind of ability of studying independently and solving problems during learning ad life. Define it as learning attitude mainly for their responsibilities of making choices for various learning, capacity means being able to solve the problems encountered during the process of independent learning and make reflection and adjustment for learning process..Bond, the famous education research expert, also points out in his study, the cultivation of students' self learning ability is an important educational goal to achieve in the teaching and education, which is also a correct education idea that all faculty members should be insisted on during teaching process, it is able to gain recognition from both teachers and students and have certain scientificalness. From the above study we can see that the cultivation of students' self learning ability in English has an important influence on the future development of the students, therefore, the university teachers should guide students to establish the correct self learning awareness during teaching processes, strengthen students' sense of learning responsibility, spur students to enhance their consciousness and ability of self-study in their future development, which will have a positive impact on the learning of other subjects on the basis of improving the effect of English learning so as to get a better development.

\section{Factors that affect college students' English self study}

\section{Learning motivation.}

Specifically speaking, English learning motivation is the learning desire and learning motivation which is. Produced during the learning process, which is able to promote college students' interest in learning and enhance learning effect. Normally, the learning motivations that can influence the 
learning ability of students includes two aspects, namely, the integration motivation and the more specific instrumental motivation .For integration motivation, it mainly means the interests learning interest about English language system itself and the culture of English speaking countries which generated during course study; Instrumental motivation mainly refers to that students take English as a learning subject during the learning process, In order to meet the needs of their own social development in the future, which is the interest generated to meet their social development in future. From the relevant research we can find that integration motivation is more permanent than instrumental motivation for college students' English learning, which can have a lasting impact on students. That is to say, in order to get a good learning effect during learning process, college students should not only take English study as a tool to meet their own development, But take English study as the main channel to improve their comprehensive quality and meet their desire to understand other civilizations, by this way, students can have a lasting learning interest and then get a better development.

\section{Learning emotion.}

Learning emotion can have an important influence on the cultivation of students' self study ability. Normally, the researchers tend to divide the learning emotion into two kinds as positive and negative during the study process, positive emotion can give students positive influence, and negative emotions can reduce the learning effect of students. That is to say, if the students maintain a positive learning status during the whole learning process, its learning efficiency will be affected and have a significant increase, which plays an important role in learning promotion. On the contrary, If students study with negative emotions, it will extremely easy to produce blind learning phenomenon, students not only can not clearly define their own learning goals but also can not choose appropriate learning strategies according to their own learning content, finally, it will have a bad effect on students' self learning effect, which is not conducive to the cultivation of students' autonomous learning ability.

\section{Teaching management.}

From the current research of domestic college students' English self learning situation and the cultivation status of students' self-study ability, in order to conform to the national call for the reform of English Education, the most majority colleges and universities have carried out appropriate adjustment and improvement of English teaching, and advocates the cultivation of students' autonomous learning ability in teaching practice and achieved certain results, which has a positive impact on the future development of the students. But during this process, there are still some universities go to the other extreme during the developing process from traditional teaching mode to autonomous learning mode, The college's English teaching management group emphasis to cultivate the students' independent learning ability too much during teaching practice, assimilate autonomic learning with self study, neglect student management, which seriously affect the teaching effect $^{[2]}$. Under this kind of teaching management system, the students who have I relatively poor control ability could not get the guidance and training of teachers , and their Self autonomous learning consciousness is relatively poor, they will gradually lost their confidence in English learning under the condition that they cannot get a better learning effect. At the same time, during the English teaching curriculum planning process, teaching management department of this kind of colleges and universities don't pay attention to students' psychological development, neglect the importance of classroom teaching for cultivating students' self study ability, and shorten the classroom teaching time, waste teaching resources and have a bad teaching effect, which dead to college English automated instruction become formalistic and lose its function.

\section{Examination oriented education model.}

Effected by examination oriented education model, students are still more concerned about their learning performance after entering college, and ignored the development of their other abilities, which causes students to memorize mechanically during learning process in order to get an ideal score, and then participate in the scholarship award selection to get more learning benefit . Some other students are affected by the current social needs and set CET four or six exam as the main goal of English learning, and in this situation, autonomous learning ability can cultivate students' 
comprehensive quality of English, But there is no great auxiliary effect on the improvement of students' learning achievement in the short term, this learning method will not draw attention from students, and the cultivation of students' autonomous learning ability cannot be realized smoothly.

\section{Teaching system.}

Teaching system general means the whole process that college English teachers develop the relative stability of teaching activities under guidance of specific teaching objectives and basic education theory . In traditional teaching system , teachers are the main body of teaching activities and have a decisive influence on English teaching, students can only passively accept the relevant knowledge in the classroom learning process, students' learning initiative and autonomy have been severely affected $^{[3]}$. So in the new period, English teachers should change the traditional ideas, take students as the main body of the teaching activities, provide efficient opportunities for students to participate in classroom activities, improve students' interest in English learning , and then gradually strengthen the autonomy of English learning ,and create conditions for students' future development .

\section{College Students English autonomous learning ability cultivation strategy}

\section{Guide and help students to establish autonomous learning awareness.}

In the process of English Teaching, the learner's own subjective will and emotional factors have an important influence on the learning effect, in college English teaching, If teachers still use traditional teaching mode, mainly rely on their teaching activities, students passively receive relevant knowledge, it is easy for students to produce mental weariness during dryasdust learning process , the learning effect will be also affected correspondingly, which is not conducive for students to develop the awareness and ability of autonomous learning. That's means, only when students maintain a positive and optimistic learning attitude during the learning process , change study idea, participate actively in classroom teaching under the teacher's education and guidance, can they give full play to their self learning initiative and lay foundations for cultivation of students' autonomous learning ability.Firstly, the teachers can explain some of the pure theoretical knowledge to the students before English teaching activities, such as the origin, development, application and the influence of the autonomous learning , let the students form an interest in autonomous learning during the learning process of theoretical knowledge, and then set up the basic consciousness of independent learning At the same time, teachers should also clear-cut the importance of developing students' autonomous learning ability in English teaching, so that students can strengthen the emphasis on Autonomous Learning. In the traditional prescriptive English teaching mode, it is very easy for students to lose their independent thinking and the ability of independent inquiry under teacher's absolute leading teaching, developing the learning habit of relying on teachers, which is not conducive to students' comprehensive development ${ }^{[4]}$ Hence, In order to make the students change the thought in the new period of study, English teachers should explain the influence of autonomous learning ability to students' comprehensive quality in the process of daily learning and the important role of autonomous learning ability in the development of high quality talents, let the students format correct understanding of independent learning gradually, so as to practice this idea in the learning process consciously and lay the foundation for the future development of the students. Lastly, teachers should strengthen communication and exchange with students in the teaching process, solve the problem of developing the students' autonomous learning ability via communication and enhance learning effect, encourage students to develop the habit of independent learning as soon as possible.

\section{The cultivation of students' English learning strategies and planning.}

Strategic learning is planning and designing for English learning systematically, which is very important for the cultivation of students' autonomous learning ability , therefore, teachers should pay more attention to the cultivation of students' English learning strategies and planning, and have a positive impact on students' study with high quality learning strategies and learning plan .Higher education stage is the period that college students should develop good learning habits and learning methods for lifelong learning, the students can only master the correct learning methods and strategy under the guidance of teachers, and complete the study plan under teacher's assistant, and gradually develop the ability of autonomous learning and lifelong learning awareness, which will lay the 
foundation for their future development . For example, for English reading problems, teachers can teach students the appropriate learning method : Combine intensive reading with extensive reading, combine with the symbolic text of the article to summarize the main idea of the article, so as to improve students' learning efficiency .

\section{Improve the basic environment of classroom teaching.}

For Higher Education English Teaching , university environment includes two aspects, which are hardware environment and software environment. Hardware environment mainly refers to the multimedia resources that teachers used in the classroom teaching process, including computer, projector, electronic whiteboard, etc, software environment mainly refers to the actual teaching ability of teachers , students learning situation and interaction between teachers and students, students and students . Normally, the teaching environment of hardware has a secondary effect on the students' learning effect, and the software teaching environment can have a decisive influence on the cultivation of students' autonomous learning ability. Therefore, the College English teachers should take appropriate teaching methods according to the student's own characteristics, stimulate students' interest in learning , and promote the students to develop the ability of autonomous learning gradually, and create conditions for students' future development . At the same time, during the teaching process, teachers should strengthen the communication and exchange with the students, construct the classroom teaching activities that take the students as the main body, and then cultivate students' autonomous learning awareness in a good environment, strengthen their autonomous learning ability and further improve students' English learning level.

\section{Flexible and diverse teaching methods.}

In order to improve the of English Autonomous Learning ability, some university use flexible and diverse teaching methods to stimulate students' interest in learning English .Firstly, they use the teaching mode of reversal classroom . Reversal classroom means reversing knowledge teaching method, internalize the knowledge and realize the role exchange between teachers and students . Meanwhile, students learn knowledge in their spare time and have knowledge consolidation and problem discussion in the classroom. For instance, during the teaching process of "American Innovators", students collect the relevant information of this article in their spare time, they can understand the content of this article through multimedia teaching. African Americans who have contributed to the field of science. He lists George Washington Carver's contributions to agriculture and Dr.Neil deGrasse Tyson's to astronomy.The inventor Bessie Blount is included,as is the 18th-century slave,Cesar,who discovered a cure for rattlesnake bites. Through autonomous learning, students can understand student can understand George Washington Carver 's contribution to agriculture and Dr Neil deGrasse Tyson's Astronomy invention. Then, students highlight and study relevant sentence patterns and grammar in the text, and raise questions . In addition, teachers make courseware according to students' needs and teaching content, make a good preparation before class, raise questions according to the article during the process of classroom teaching, such as what's the article mainly talking about? What sentence patterns are included in the article? At the same time, the students also put forward the question to teachers and other students. Then, teachers create a good learning environment for students, use reversal classroom teaching mode through mutual exchange to ensure that students can master a good learning method; secondly, they carry out micro teaching. Micro teaching means they make the video as the main body of the teaching, integrate teaching resources and make full use of network teaching mode under the new curriculum standards .The universities can record the micro lesson of the optional English textbook, students can watch the video on Campus web ,such as Experience English, New Perspective College English . At the same time, teachers can also select the classic English reading materials for students' appreciation in the classroom. Therefore, teachers provide a good basis for the cultivation of College Students' autonomous learning ability via using of flexible and diverse teaching methods.

\section{Pay attention to formative assessment and self assessment.}

Pay attention to formative assessment and self assessment is also the main measure of cultivating college students' English autonomous learning ability. Therefore, universities must establish a file for every student during teaching process and evaluate teaching content and students' learning process in 
order to provide reference for future teaching .Firstly, Formative assessment including students' English reading ability, English test scores of each semester, English writing level, autonomous Learning and creative ability, etc., then teachers, parents, groups, etc., make evaluation for students' personal comprehensive status. For group evaluation, students play the role of mutual supervision through cooperative learning. At the same time, teachers and parents mark on students' English classroom learning and home learning status, the schools will archive students' assessment results, and then provide a good basis for the development of English teaching. In addition, Students also need to conduct self evaluation, make objective evaluation of the learning process, learning attitude and method through English learning process, avoid subjective color and must evaluate fairly, make comprehensive assessment of themselves , and then find the problems in English learning. Therefore, pay attention to formative evaluation and self evaluation can help students improve their learning ability during the process of English learning, students can find out problems through comprehensive assessment and put forward the best method of English learning,finally improve English achievement.

\section{Conclusion}

Cultivation of students' autonomous learning ability is the main goal of English Teaching in China at present, which has a positive impact on students' lifelong learning. In order to achieve this goal, university English education departments should explore new teaching methods and the education ideas actively in our country, take some measures to activate students' English autonomous learning motivation, and then gradually develop the habit of independent learning and lay the foundation for the future development of the students. At the same time, on this basis, English education department should also re-planning course teaching system by using the existing academic atmosphere, and give full play to teachers' leading role in teaching and students' subjective role, promoting the reform of English education effectively

\section{References}

[1] Li Houye. The influence factors and ability training of College students' English autonomous learning [J]. Impart knowledge and educate people (Higher Education Forum), 2013(6):92-93.

[2] Li Lixia. A survey of autonomous learning consciousness and self learning ability of College Students.Shanghai Normal University, 2011

[3] Zhao Wei, Wang Shengjie. Analysis of the influence factors of Higher Vocational Students' English Autonomous Learning. Youth years, 2014(14):267-267

[4] Rao Weizhong. The analysis of the influence factors and training strategies of College English autonomous learning ability. Journal of Fujian College of Education. 2012(3):91-94.

[5] Chen Feng, Discussion on English autonomous learning in the context of Graded Teaching. Huazhong Normal University; 2011. 